\title{
Contributing factors to academic achievements: from community college to university in Hong Kong
}

\section{Yee-na $\mathrm{Li}^{1}$, Bin $\mathrm{Li}^{1}$, Kin Cheung ${ }^{2}$, Hilda Tsang ${ }^{2}$}

${ }^{1}$ Department of Linguistics and Translation, City University of Hong Kong, Hong Kong, China, ${ }^{2}$ School of Nursing, The Hong Kong Polytechnic University, Hong Kong, China.

\begin{abstract}
Academic achievement of students transferring from community colleges to 4-year institutions has been a topic of interest to educational researchers globally. However, local empirical evidence remains limited on how transfer students' learning approaches and the teaching-learning environment relate to their academic achievement in Hong Kong's universities. The study aims at exploring the relationship between transfer students' approaches to learning, their perceptions of the teaching-learning environment and academic achievement. The participants were 617 undergraduate students transferring from community colleges to an university in Hong Kong. Students' approaches to learning and perceptions of the teaching-learning environment were measured using the HowULearn questionnaire. Analyses were carried out using factor analysis, Pearson correlation and linear regression. The results confirmed positive relations between students' perceptions, approaches and achievement. Students studying in an organised manner achieved better academic performance, whereas those using a surface approach poor performance. Others might also adopt an intermediate approach to learning. The results indicate that promoting awarenesses of choosing and using appropriate learning approaches is important for fostering academic success among students.
\end{abstract}

Keywords: Approaches to learning; Perceptions of the teaching-learning environment; academic achievement; Community college transfers. 


\section{Introduction}

Community colleges, in addition to a direct admission to universities after the completion of secondary education, have been a second pathway to an undergraduate degree. In Hong Kong, students with two-year associate degrees or higher diploma levels (which are collectively known as "sub-degree") can transfer from community colleges to universities based on a credit unit transfer system. They are admitted to the third-year study of a degree programme and will receive the degree in two years (Yung, 2002). The number of subdegree graduates transferring to four-year institution is recorded growing annualy in recent years, which warrants closer attention and comprehensive study on their post-transfer learning experiences and academic achievement. Sub-degree students may often encounter difficulties in adjusting to a new learning environment, which is referred to as "transfer shock" (Hill, 1965). Some studies reported that transfer students had a lower academic achievement than non-transfer students (e.g. Cameron, 2005). On the other hand, some reported that transfer students were academically more successful compared to non-transfer students (e.g. Martinello \& Stewart, 2013). Despite the mixed results in the literature, the academic performance of transfer students has long been of considerable interest to researchers, and thus identifying factors that will facilitate transfer students' educational attainment remains an important goal.

The relationships between students' approaches to learning (SAL), perceptions of the teaching-learning environment (TLE) and academic achievement have been widely examined in higher education contexts (e.g. Asikainen et al., 2014; Rytkönen et al., 2012). Approaches to learning, referring to the nature of students' study processes, have been classified into three approaches: a deep approach refers to the ability to understand, to relate and to construct meaning in the learning material; a surface approach is related to memorising without aiming at understanding; and, a strategic approach, labeled as an organised studying, refers to the ability to manage time and effort (Entwistle \& McCune, 2004). Previous studies indicate that the deep approach and organised studying are positively related to academic achievement, and the surface approach negatively related (e.g. Tuononen et al., 2019), although contradictory results have also been found (Lizzio et al., 2002). SAL have been found to depend greatly on their perceptions of the teachinglearning environment. Evidence showed that effective teaching, which is relevant, interesting, constructively aligned, and supports students' understanding, along with constructive feedback and support from staff and peers, could facilitate the use of a deep approach and an organised studying (Postareff et al., 2018).

Although a number of studies have also examined how transfer students' perceptions of the academic environment is related to academic adjustment (Flaga, 2006), little effort involving quantitative measures has been documented in the literature on their correlations with SAL. Acai and Newton (2015) have compared transfer students and those via direct- 
entry from high schools in Ontario, and found no significant difference in their learning approaches or academic achievements. To better understand how transfer students' learning could be more effectively accommodated under the higher education system in Hong Kong, this study aims at exploring the relationships between perceptions of the TLE, SAL and academic achievement.

\section{Method}

\subsection{Instrument}

We designed a questionnaire based on two validated inventories: Experiences of Teaching and Learning Questionnaire (ETLQ; Entwistle et al., 2003) and the Approaches to Learning and Studying Inventory (ALSI; Entwistle \& McCune, 2004). Items are scored on a fivepoint Likert scale ( $1=$ totally disagree, $5=$ totally agree). The instrument has been validated across contexts (Parpala et al., 2013). Our questionnaire for this study contained a part of demographic information such as gender and age, followed by two sections from the HowULearn Questionnaire (Parpala \& Lindblom-Ylänne, 2012), which measures students' perceptions of the TLE (22 items) and SAL (12 items). Revision was made on on some region-applicable items to fit the local use. The whole questionnaire was then reviewed by a panel of nine overseas and local experts in the education field to determine the content validity index (CVI). A CVI of 0.99 was found, which was higher than the acceptable level of 0.75 . Eleven undergraduate students were invited to fill in the questionnaire to test its readability and appropriateness. Minor changes in the wording were then made on some items. Students' academic achievement was measured by calculating a grade point average (GPA) at the time of data collection.

\subsection{Participants and Data Collection}

The questionnaire was posted online to collect data from September 2018 to November 2019, using convenience sampling. All full-time transfer students in government-funded degree programmes in $\mathrm{X}$ University in Hong Kong were inivited electronically to participate in the study. A total of 617 responses were obtained. The participants were from 27 departments involving all faculties and schools in the university. The sample consisted of $59.3 \%$ female and $40.7 \%$ male students, aged 18 to 41 years $(\mathrm{M}=22.31, \mathrm{SD}=1.78)$.

\subsection{Data Analysis}

SPSS analytical software version 25 was used for the data analysis. We conducted exploratory factor analyses (EFA) for each construct by using the general rule of an eigenvalue > 1 (Kaiser, 1960), and used the maximum likelihood extraction method and oblimin rotation. The Kaiser-Meyer-Olkin (KMO) test was conducted to measure the 
sampling adequacy. Cronbach's alpha statistics were computed to test the scales' internal consistency. The presence of multicollinearity among the independent variables was examined by the tolerance values and the variance inflation factor (VIF) for the data included in the analysis. Confirmatory factor analyses (CFA) using SPSS AMOS 25 were conducted on thenew factors emerged from EFA. The fit of the model was assessed using the chi-square test of model fit, the goodness-of-fit index (GFI), the Tucker-Lewis index (TLI), the comparative fit index (CFI), and the root mean square error of approximation (RMSEA). Pearson's correlation test was used to test the correlations between the scales of the TLE, SAL, and academic achievement. Variables with statistically significant correlations with academic achievement were selected for the linear regression analysis (forward) to explore its strongest predictor.

\section{Results}

\subsection{Factor Analyses}

The factor structures of the items measuring students' perceptions of the teaching and learning environment were different from the original study by Parpala et al. (2012), as shown in Table 1. Three factors were labelled as teaching for understanding \& encouraging learning (FE1), peer support (FE2), and alignment \& constructive feedback (FE3). The factor loadings ranged between 0.34 and 0.90 , which explained $50.0 \%$ of the total variance. Table 1 shows the main descriptive statistics. In line with the original study, three factors measuring SAL were loaded, ranging between 0.31 and 0.81 (see Table 2). They were labelled as organised studying (FA1), deep approach (FA2) and surface approach (FA3), which explained $44.5 \%$ of the total variance.

Table 1. Descriptive statistics for subscales of Teaching and Learning Environment (22 items).

\begin{tabular}{|c|c|c|c|c|}
\hline & Items & $\mathbf{M}$ & SD & $\alpha$ \\
\hline FE1 & $1,2,3,4,5,6,7,9,10,12,13,14,16$ & 3.59 & 0.55 & 0.92 \\
\hline FE2 & $8,11,15$ & 3.65 & 0.72 & 0.77 \\
\hline FE3 & $17,18,19,20,21,22$ & 3.43 & 0.66 & 0.88 \\
\hline
\end{tabular}


Table 2. Descriptive statistics for subscales of Students' Approaches to Learning (12 items).

\begin{tabular}{llccc}
\hline \multicolumn{2}{c}{ Items } & M & SD & $\boldsymbol{\alpha}$ \\
\hline FA1 & $2,4,8,10$ & 3.49 & 0.60 & 0.73 \\
FA2 & $5,6,11,12$ & & & \\
FA3 & $1,3,7,9$ & 3.52 & 0.57 & 0.75 \\
\hline
\end{tabular}

The tolerance values ranged from 0.311 to 0.808 , and the VIF values ranged from 1.238 to 3.213. Since the VIF values were between 1 and 10, we concluded that no instance of excessive collinearity among the independent variables was evident in the data. From the results of CFA on SAL, the chi-square test $(\chi 2=219.9, \mathrm{df}=51, \mathrm{p}<.001)$ indicated a poor fit; however, this was expected due to the large sample. The fit indices (GFI=.944, CFI=.914, TLI=.888, RMSEA=.073) were acceptable. For the CFA on students' perceptions of the teaching and learning environment, the chi-square test indicated a poor fit $(\chi 2=871.3$, $\mathrm{df}=206, \mathrm{p}<.001$ ), while the fit indices $(\mathrm{GFI}=.881, \mathrm{CFI}=.905$, TLI=.893, RMSEA=.072) were reasonable. This suggested that the factor structures of the subscales fitted the data reasonably well.

\subsection{The relationships between academic achievement, SAL and perceptions of the TLE}

Statistical results are listed in Table 3, which shows correlations between academic achievement, perceptions of the TLE and SAL. Positive correlations were observed between all teaching-learning environment factors and between all SAL factors. In addition, the perceptions correlated positively with deep approach and organised studying, but not significantly correlated with surface approach. The results showed statistically significant positive correlations between academic achievement and teaching for understanding \& encouraging learning, deep approach and organised studying, and a statistically significant negative correlation between academic achievement and surface approach. In other words, peer support and alignment $\&$ constructive feedback were the only factors that were unrelated to academic achievement.

In addition, regression analyses were conducted to explore which factors had the strongest relationship with academic achievement. The results showed that surface approach to learning $(\beta=-.15, \mathrm{p}<.001)$ and organised studying $(\beta=.13, \mathrm{p}<.01)$ were the predictors of academic achievement. 
Table 3. Relation between students' perceptions of the TLE, SAL and academic achievement

\begin{tabular}{|c|c|c|c|c|c|c|c|}
\hline Factor & 1 & 2 & 3 & 4 & 5 & 6 & 7 \\
\hline 1. FE1 & 1 & & & & & & \\
\hline 2. FE2 & $.595 * *$ & 1 & & & & & \\
\hline 3. FE3 & $.736 * *$ & $.483 * *$ & 1 & & & & \\
\hline 4. FA1 & $.404 * *$ & $.330 * *$ & $.352 * *$ & 1 & & & \\
\hline 5. FA2 & $.515 * *$ & $.335 * *$ & $.394 * *$ & $.549 * *$ & 1 & & \\
\hline 6. FA3 & -.038 & .024 & -.005 & $.236 * *$ & $.186 * *$ & 1 & \\
\hline 7. Academic achievement & $.121 * *$ & .031 & .053 & $.154 * *$ & $.121 * *$ & $-.139 * *$ & 1 \\
\hline
\end{tabular}

$* * \mathrm{p}<0.01$, statistically significant correlations shown in bold

\section{Discussion}

The present study explored how students' perceptions of their TLE and SAL are related to their academic achievement. The results showed that positive perceptions of the TLE are related to the use of a deep learning approach and an organised studying, which is in line with earlier research (e.g. Entwistle et al., 2003 ; Rytkönen et al., 2012; Postareff et al., 2018). Similarly, the results resonated with previous studies in which the deep approach and organised studying were related to a better academic performace and the surface approach to a poor performace (e.g. Lizzio et al., 2002). This confirms the widely accepted idea that students' perceptions of the TLE and SAL are important factors for academic success.

Our analysis of what predicts students' academic achievement supports the findings in Rytkönen et al. (2012) that organised studying had stronger relations with academic achievement than deep approach to learning. This may be partly due to the nature of deep approach, as grade point average is not necessarily the best way to measure the quality of the learning outcomes related to deep approach (Rytkönen et al. 2012). On the other hand, time management and organised studying are important for transfer students' successful studying at university. They are often faced with heavy study loads due to a poor subject alignment between sub-degree and degree programmmes and inadequate support for transitioning (Cheung et al., 2015), and the needs to balance study with non-academic activities such as paid work or family commitments (e.g. Briggs et al., 2012). Therefore, they have to pay special attention on how to schedule their time well to fufil their study requirements. 
Interstingly, although transfer students scored slightly higher on the deep learning and organised studying than the surface learning, a significant and positive correlation between surface learning and deep learning with organised studying was found, differing from the results of previous studies (e.g. Rytkönen et al., 2012) that surface approach was negatively related to the other two approaches. The inconsistence may be explained by the intermediate approaches used by the students (Kember, 2016). Contrary to the commonly held belief that the characterisation of deep and surface approaches to learning was dichotomous, there is evidence of Chinese students using mixed approaches to learning, intermediate between pure surface and deep approaches, which combine memorising and understanding (see Kember, 2016 for a review). This indicates that students tended to understand the concepts in their learning process, and at the same time recognized the role of memorisation played in their examinations. Nevertheless, it should be noted that there are distinct forms of memorisation (Kember, 2016). Although both intermediate and pure surface approaches involve memorisation, rote learning or mechanical memorization only in a pure surface approach to learning should lead to poor learning outcomes, which is supported by the results of regression analyses in the present study.

The present study and findings underline the importance of transfer students' awarenesses and development of effective skills for successful learning in universities. A supportive mechanism from universities is most desirable to facilitate students to achieve these goals and to develop habits in autonomous leanring. Institutional supports could include enhancement on pedagogical relevance and interests in learning, as well as on constructive feedback and assessment. These supportive means could help students articulate individual learning needs and self-evaluate their learning outcomes against a programme's objectives. Workshops could also be provided on fostering skills for organized studying such as time management skills, and activities be organized on promoting awareness of strategies and approaches to effective learning. These pedagogical measures are crucial and facilitative for transfer students to successfully adapt to university study and to obtain academic achievements.

\section{References}

Acai, A., \& Newton, G. (2015). A Comparison of Factors Related to University Students' Learning: College-Transfer and Direct-Entry from High School Students. Canadian Journal of Higher Education, 45(2), 168-192.

Asikainen, H., Parpala, A., Lindblom-Ylänne, S., Vanthournout, G., \& Coertjens, L. (2014). The Development of Approaches to Learning and Perceptions of the TeachingLearning Environment during Bachelor Level Studies and Their Relation to Study Success. Higher Education Studies, 4(4), 24-36. doi: 10.5539/hes.v4n4p24. 
Briggs, A. R., Clark, J., \& Hall, I. (2012). Building bridges: understanding student transition to university. Quality in Higher Education, 18(1), 3-21. doi: 10.1080/13538322.2011.614468.

Cameron, C. (2005). Experiences of transfer students in a collaborative baccalaureate nursing program. Community College Review,33(2), 22-44. doi: $10.1177 / 009155210503300202$.

Cheung, K., Lai, P., Yick, K. L., \& Chan, S. W. (2015). Perception of the teaching-learning environment and learning approaches on the academic results of senior-year admitted (SYA) students. Paper presented at the international conference: Assessment for Learning in Higher Education 2015, 14-15 May 2015, Hong Kong.

Entwistle, N., \& McCune, V. (2004). The conceptual bases of study strategy inventories. Educational Psychology Review, 16(4), 325-345. doi: 1040-726X/04/12000325/0.

Entwistle, N., McCune, V., \& Hounsell, J. (2003). Investigating ways of enhancing university teaching-learning environments: Measuring students' approaches to studying and perceptions of teaching. In De Corte, E., Verschaffel, L., Entwistle, N. \& van Merrienboer, J. (Eds.), Unravelling basic components and dimensions of powerful learning environments, Oxford: Elsevier Science.

Flaga, C. T. (2006). The process of transition for community college transfer students. Community College Journal of Research and Practice, 30(1), 3-19.

Hills, J. R. (1965). Transfer shock: The academic performance of the junior college transfer. The Journal of Experimental Education,33(3), 201-215. doi: 10.1080/00220973.1965.11010875

Kaiser, H. F. (1960). The application of electronic computers to factor analysis. Educational and psychological measurement,20(1), 141-151. doi: 10.1177/001316446002000116.

Kember, D. (2016). Why do Chinese students out-perform those from the West? Do approaches to learning contribute to the explanation?. Cogent Education, 3(1), 1248187. doi: 10.1080/2331186X.2016.1248187.

Lizzio, A., Wilson, K., \& Simons, R. (2002). University students' perceptions of the learning environment and academic outcomes: implications for theory and practice. Studies in Higher education, 27(1), 27-52. doi: 10.1080/03075070120099359.

Martinello, F., \& Stewart, J. (2013). Transfers from college to university: A four-year outcome study. Retrieved from http://www.ontransfer.ca/www/files_docs/content/pdf/ en/student_pathways_conference/2013/stewart_martinello_fri.pdf

Parpala A., \& Lindblom-Ylanne S. (2012). Using a research instrument for developing quality at the university. Quality in Higher Education, 18(3), 313-328. doi: 10.1080/13538322.2012.733493

Parpala, A., Lindblom-Ylänne, S., Komulainen, E., \& Entwistle, N. (2013). Assessing students' experiences of teaching-learning environments and approaches to learning: Validation of a questionnaire in different countries and varying contexts. Learning Environments Research, 16(2), 201-215. doi: 10.1007/s10984-013-9128-8. 
Postareff, L., Mattsson, M., \& Parpala, A. (2018). The effect of perceptions of the teachinglearning environment on the variation in approaches to learning-Between-student differences and within-student variation. Learning and Individual Differences, 68, 96107. doi: 10.1016/j.lindif.2018.10.006.

Rytkönen, H., Parpala, A., Lindblom-Ylänne, S., Virtanen, V., \& Postareff, L. (2012). Factors affecting bioscience students' academic achievement. Instructional Science, 40(2), 241-256. doi: 10.1007/s11251-011-9176-3.

Tuononen, T., Parpala, A., \& Lindblom-Ylänne, S. (2019). Complex interrelations between academic competences and students' approaches to learning-mixed-methods study. Journal of Further and Higher Education, 1-18. doi: 10.1080/0309877X.2019.1648776.

Yung, M. S. (2002). Community college: A new born baby of the Hong Kong education system for the new millennium. Hong Kong Teachers' Centre Journal, 1, 32-44. 